http://dx.doi.org/10.1590/1678-4162-8534

Arq. Bras. Med. Vet. Zootec., v.68, n.2, p.404-414, 2016

\title{
O mexilhão Perna perna no Brasil: nativo ou exótico?
}

[The brown mussel Perna perna in Brazil: native or exotic?]

B.S. Pierri, T.D. Fossari, A.R.M. Magalhães

Universidade Federal de Santa Catarina - Florianópolis, SC

\section{RESUMO}

A mitilicultura no Brasil se baseia no mexilhão Perna perna (Linnaeus, 1758), que é encontrado em todo o litoral brasileiro, sendo especialmente abundante do Espírito Santo a Santa Catarina. Nos últimos anos, foi lançada a hipótese de que P. perna seja uma espécie exótica no litoral brasileiro. A hipótese se baseia na análise da malacofauna presente em sítios arqueológicos. Todas as contestações levantadas não remetem à uma conclusão, pois precisam de estudos específicos, com metodologias claras, aliando arqueologia, ecologia e biologia molecular. O objetivo deste trabalho foi estudar a condição de nativo ou exótico do mexilhão Perna perna no Brasil, a partir de levantamento dos resultados em sítios arqueológicos, de técnicas moleculares e de datação de conchas com $\mathrm{C}^{14}$. A datação indicou que as amostras de Perna perna do sítio arqueológico Rio do Meio/Jurerê, Florianópolis/SC, têm idade de $720 \pm 30$ e $780 \pm 30$ anos. O cálculo do tempo de divergência indicou que a separação das populações brasileiras e africanas ocorreu por volta de 200 mil anos. Os resultados apontam a presença da espécie no território brasileiro muito antes do descobrimento do Brasil pelos portugueses no ano de 1500, indicando que $P$. perna é de fato uma espécie nativa.

Palavras-chave: aquicultura, cultivo, moluscos, mitilicultura

\begin{abstract}
Mussel farming in Brazil is based on brown mussel Perna perna (Linnaeus, 1758), which is found throughout the Brazilian coast, especially abundant from Espírito Santo to Santa Catarina coast. In recent years it was suggested that Perna perna is an exotic species for the Brazilian coast. The hypothesis is based on the analysis of the zooarchaeology studies in archaeological sites in Brazil. All objections raised do not offer a conclusion, because they need specific studies with clear methodology, combining archeology, ecology and molecular biology. The aim of this work was to study the condition of the brown mussel Perna perna in Brazil if native or exotic, from survey results in archaeological sites, molecular techniques and dating of shells with $C^{14}$. The dating indicated that the shells were $720 \pm 30$ and $780 \pm 30$ years, respectively. The calculation of divergence time indicated that the separation of the African and Brazilian mussel populations occurred around 200 thousand years ago. The results indicate the presence of the P. perna species in Brazilian territory long before the discovery of Brazil by the Portuguese in 1500 , indicating that P. perna is actually a native species of Brazil.
\end{abstract}

Keywords: aquaculture, seafarm, mollusc, mussel farm

\section{INTRODUÇÃO}

Nos últimos séculos, milhares de espécies têm sido dispersas para locais fora de sua distribuição geográfica natural e têm transformado o ecossistema marinho no mundo (Ruiz et al., 1997; Mack et al., 2000). Mesmo que as espécies

Recebido em 21 de junho de 2015

Aceito em 22 de setembro de 2015

E-mail: pierri.bruno@hotmail.com exóticas sejam hoje reconhecidas como importantes causadoras de impacto à biodiversidade mundial (Mcgeoch et al., 2010), pouco se sabe sobre a dispersão dessas espécies em escala global (Hulme, 2009). Considerada uma grande causadora da dispersão de espécies exóticas no planeta (Ruiz et al., 1997), a água de lastro de navios vem se tornando fonte de estudos científicos. 
Atualmente, vem sendo discutida a hipótese de que o mexilhão Perna perna (Linnaeus, 1758) seja uma espécie exótica do litoral do Brasil, tendo sido introduzida no país há pouco mais de 400 anos, devido ao tráfego de navios negreiros oriundos do continente africano, que, de acordo com Fernandes (2008), é tido como o berço dessa espécie. A hipótese é baseada principalmente em estudos de análise da malacofauna presente em sambaquis no litoral sudeste do Brasil. Souza et al. (2003, 2010) argumentam que a ausência desses bivalves em sítios arqueológicos seja uma comprovação de sua condição invasora.

A espécie Perna perna apresenta grande importância para os ambientes em que habita, estruturando a comunidade em litorais rochosos e sendo bioatratora de diversidade (Freitas e Velastin, 2010). Apresenta também características desejadas para a aquicultura, como rápido crescimento (Ferreira e Magalhães,
2004; Marenzi e Branco, 2006) e resistência a variações nos parâmetros físico-químicos da água, entre eles salinidade (Salomão et al., 1980) e temperatura (Vélez e Epifanio, 1981; Hicks e McMahon, 2002).

O mexilhão é uma relevante fonte de renda para as famílias que realizam seu cultivo. A mitilicultura no Brasil se baseia na produção dessa espécie, que apresenta ampla distribuição geográfica (Fig. 1) e é encontrada com abundância em quase toda a extensão do litoral brasileiro (Rios, 2009). Porém, sua condição de espécie exótica foi responsável pela proibição do cultivo em alguns estados do país. Nesse contexto, o conhecimento da origem da espécie no território brasileiro, por meio de métodos científicos, faz-se necessário e, para tanto, técnicas moleculares e arqueológicas são ferramentas aplicáveis na tentativa de se esclarecer essa questão.

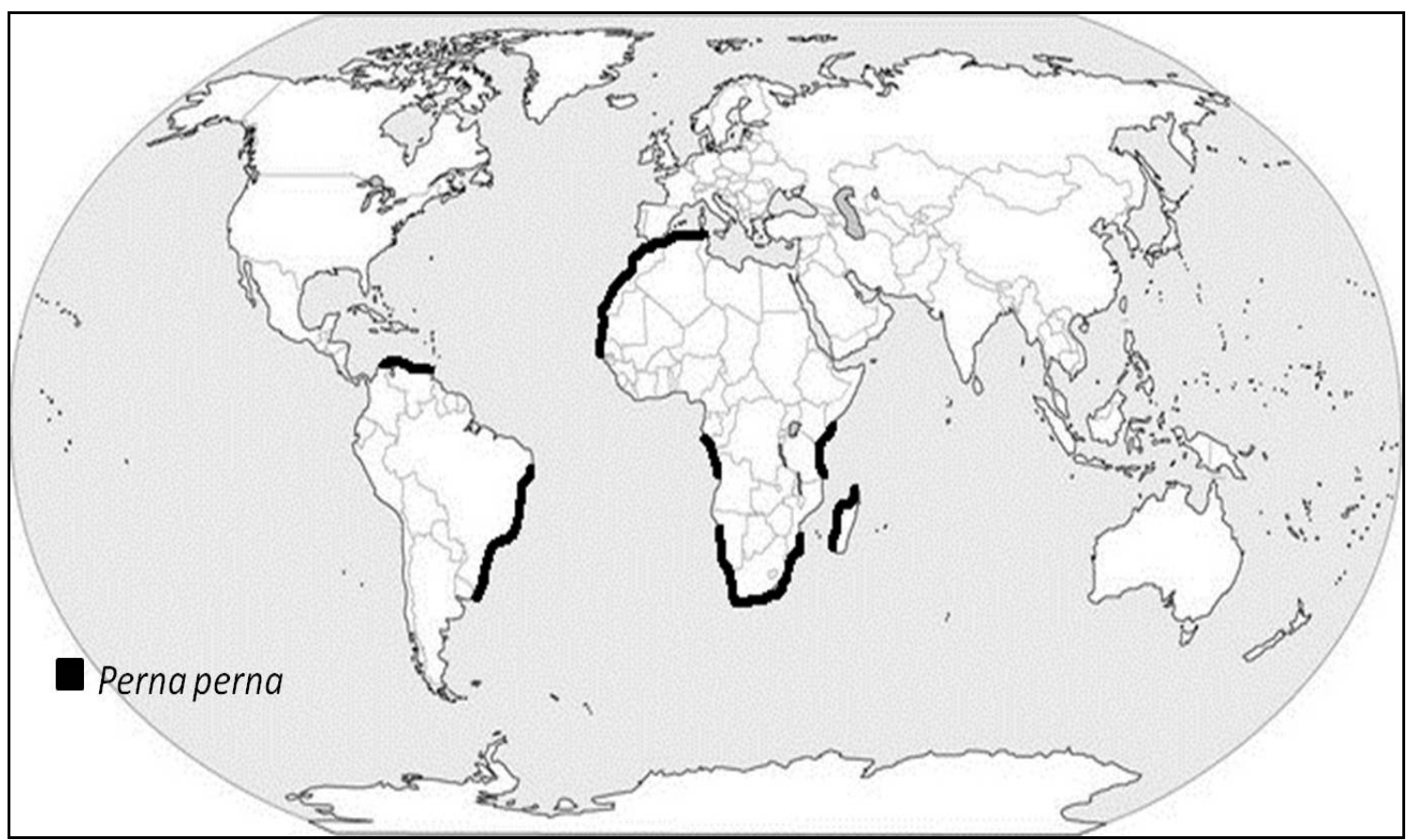

Figura 1. Distribuição geográfica do mexilhão Perna perna.

Todos os organismos estão sujeitos a mutações como resultado de operações celulares normais ou de interações com o meio ambiente, levandoos à variação genética (Liu e Cordes, 2004). Genes mitocondriais possuem taxas de mutação elevadas, o que pode ser atribuído a uma taxa mais rápida de mutação no DNA mitocondrial
(Birky et al., 1989). Utilizando-se bancos de dados, é possível selecionar sequências de genes para realizar as análises moleculares desejadas. Em estudo com o gênero Perna, Folmer et al. (1994) encontraram genes mitocondriais de aproximadamente 650 pares de base da subunidade I da citocromo c oxidase (COI). Esse 
gene tem permitido a realização de estudos filogenéticos comparativos.

Outra ferramenta que pode auxiliar na discussão sobre a condição de invasora da espécie é a datação com $\mathrm{C}^{14}$. Muitos trabalhos, como os de Vellanoweth (2001), Takada et al. (2003), Rick et al. (2005), Wanamaker Jr. et al. (2008), Kilada et al. (2009), Cooper e Thomas (2012), vêm aplicando essa técnica em conchas de moluscos ao redor do planeta. $\mathrm{Na}$ datação com radiocarbono, a espectrometria de massa com aceleradores (AMS) vem ganhando destaque no mundo da pesquisa, por se tratar de uma metodologia mais atual e apresentar resultados com níveis de confiança mais elevados.

Este trabalho teve como objetivo contribuir para a compreensão da origem da espécie Perna perna no litoral brasileiro, utilizando-se técnicas moleculares e datação com $\mathrm{C}^{14}$ em conchas coletadas em sítio arqueológico, além da consulta à bibliografia existente sobre malacofauna arqueológica brasileira.

\section{MATERIAL E MÉTODOS}

Foi realizado levantamento bibliográfico, a fim de encontrar citações da espécie Perna perna ou sinonímias em registros arqueológicos ao longo do território brasileiro que tenham sido ou não datados com $\mathrm{C}^{14}$.

Em seguida, foi realizado um levantamento da reserva técnica do Museu de Arqueologia e Etnologia Oswaldo Rodrigues Cabral (MArquE) da Universidade Federal de Santa Catarina (UFSC). Após estudar o material contido no acervo, foram coletados fragmentos e conchas do mexilhão Perna perna do sítio arqueológico Rio do Meio.

O sítio Rio do Meio (Fig. 2-A) localizava-se na região noroeste de Florianópolis/Santa Catarina Brasil, junto à parte média da praia de Jurerê, em terreno pertencente à Marinha do Brasil. O sítio recebeu este nome da população local em alusão a um rio que cortava a região, hoje aterrado. $\mathrm{O}$ acervo malacológico do sítio Rio do Meio foi reunido a partir das escavações sistemáticas realizadas entre os anos de 1986 e 1989, coordenadas pela arqueóloga do MArquE Teresa Domitila Fossari.

Duas amostras de concha (I e II) do sítio arqueológico foram coletadas para datação. As amostras foram coletadas de duas diferentes subdivisões que formavam o sítio Rio do Meio (Áreas I e II). A amostra I foi coletada da base da Área I, ou seja, da parte mais profunda do sítio, e a amostra II foi coletada no nível 3 da Área II. Após a coleta, as amostras foram analisadas pela empresa Beta Analytic Inc. (Miami, EUA) utilizando-se a técnica de acelerador de espectrometria de massa (AMS) para a datação por $\mathrm{C}^{14}$ (Bennett et al., 1977). O ponto de calibração $(\Delta R)$ para as duas amostras foi de 117 . Diferentemente dos demais trabalhos que realizaram a datação de sítios arqueológicos brasileiros, este trabalho utilizou conchas da espécie Perna perna em vez de carvão, para a datação por radiocarbono.

Dez mexilhões da espécie Perna perna foram coletados junto ao cultivo experimental do Laboratório de Moluscos Marinhos (Fig. 2-B) da Universidade Federal de Santa Catarina (LMMUFSC), na praia do Sambaqui-Florianópolis/SC (27\%49'23's e 48 53'47'W), para ser realizado o sequenciamento do gene mitocondrial citocromo oxidase subunidade I (COI).

O DNA total dos animais foi extraído da glândula digestiva, mediante o uso do kit DNeasy Tissue Kit (QUIAGEN, Austrália). Aproximadamente $620 \mathrm{pb}$ do gene foram amplificados utilizando-se os primers LCO1490, 5' - GGTCAACAAATCATAAAGATATTGG-3' e HCO2198, 5'-TAAACTTCAGGGTGACCAAAAAATCA3'. As reações de PCR foram realizadas contendo $20 \eta \mathrm{g}$ de DNA total, $0,5 \mu \mathrm{M}$ de cada primer, $200 \mu \mathrm{M}$ de cada dNTP, $5 \mu \mathrm{L}$ de solução-Q (QUIAGEN, Austrália), 1x Qiagen PCR buffer em $25 \mu \mathrm{L}$ de volume de reação. A desnaturação inicial de dois minutos a $94^{\circ} \mathrm{C}$ foi seguida por 35 ciclos de $94^{\circ} \mathrm{C}$ por 30 segundos, $50^{\circ} \mathrm{C}$ por 30 segundos, $72^{\circ} \mathrm{C}$ por um minuto e uma extensão final a $72^{\circ} \mathrm{C}$ por cinco minutos. 


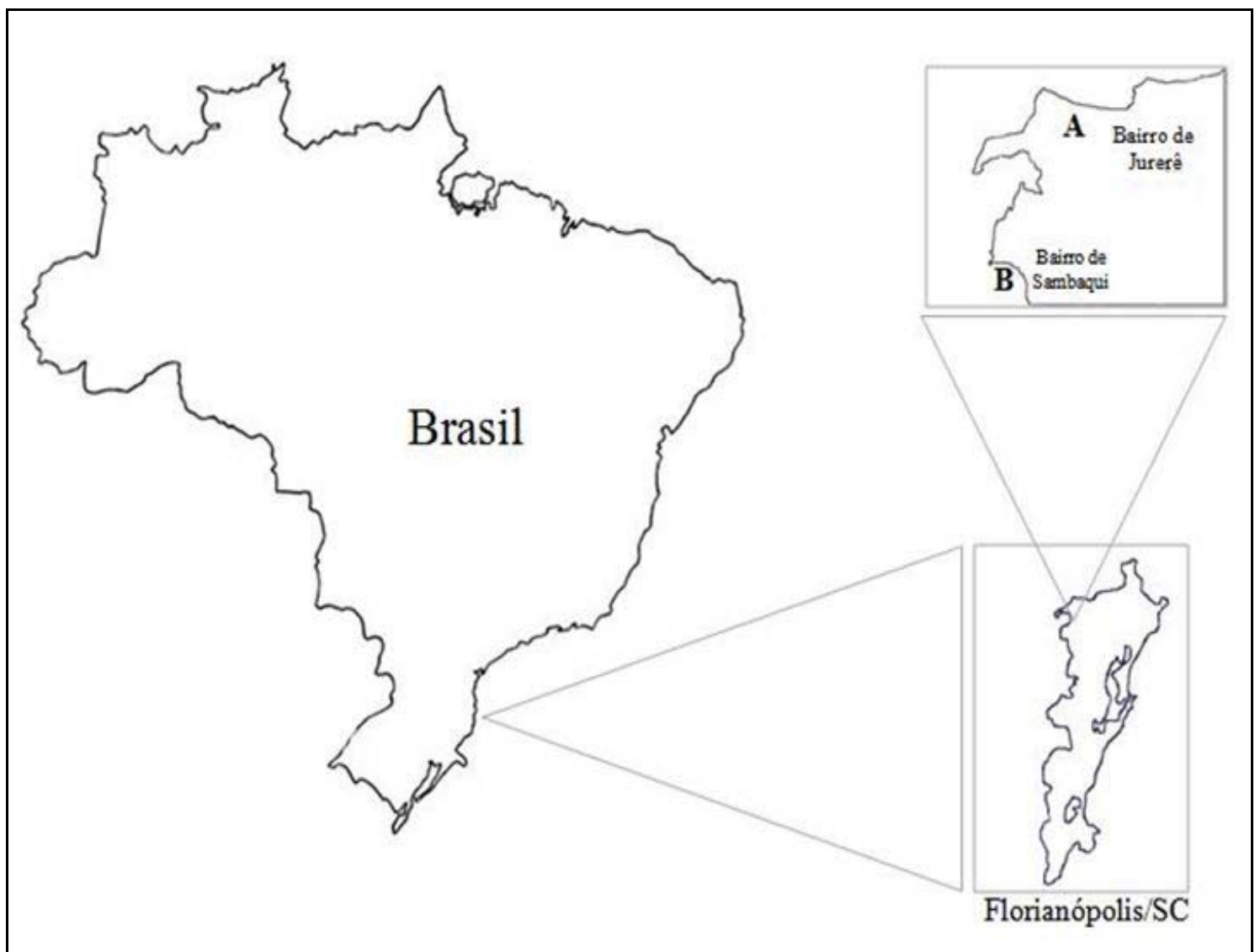

Figura 2. Localização do sítio arqueológico Rio do Meio (A) e da praia do Sambaqui (B) em Florianópolis/SC, Brasil.

Os produtos de PCR foram separados em gel de agarose $2 \%$ e purificados, utilizando-se o kit MinElute Gel Extraction Kit (QIAGEN, Austrália). Após a purificação, o inserto foi ligado ao vetor pGEM-TM Easy (PROMEGA, Estados Unidos), com posterior transformação em bactérias cálcio competentes DH5 $\alpha$. As bactérias transformadas foram aplicadas em placa de ágar 35g/L (LB Agar-SIGMA) contendo ampicilina $(100 \mathrm{mM})$, IPTG $(0,5 \mathrm{mM})$ e X-GAL $(50 \mathrm{mM})$, por um período de 18 horas, a $37^{\circ} \mathrm{C}$, para o crescimento das colônias. As colônias de cor branca foram repicadas para meio de cultura líquido 20g/L (LB Broth -SIGMA) contendo $100 \mathrm{mM}$ de ampicilina e mantidas durante 18 horas a $37^{\circ} \mathrm{C}$ em agitação constante (140rpm). A extração plasmidial para sequenciamento foi realizada por meio de lise alcalina das colônias crescidas em $1 \mathrm{~mL}$ de meio líquido, nas mesmas condições descritas anteriormente, utilizando-se o kit QIAprep ${ }^{\circledR}$ Spin Miniprep Kit (QIAGEN, Alemanha). As amostras foram sequenciadas no sequenciador 3130 Genetic Analyzer ${ }^{\circledR}$ (Applied Biosystem, HITACHI). Todas as análises moleculares foram realizadas no Laboratório de Biomarcadores de Contaminação Aquática e Imunoquímica (Labicai-UFSC).

Para comparação, sequências do gene COI de $P$. perna de outras regiões do planeta foram coletadas no NCBI. As sequências selecionadas (Tab. 1) foram alinhadas usando-se o Clustal W, implementado no programa MEGA v. 5.0 (Tamura et al., 2011), utilizando as configurações-padrão do software. O alinhamento ocorreu de forma simples e nenhum par de bases foi excluído das sequências. 
Tabela 1. Sequências do gene subunidade I do citocromo c oxidase (COI) utilizadas na análise filogenética de diferentes populações de mexilhão Perna perna

\begin{tabular}{llll}
\hline Espécie & Localização & Código & GenBank\# \\
\hline & Leste da África do Sul & AF1 & DQ917618 \\
& Leste da África do Sul & AF2 & DQ917617 \\
& Leste da África do Sul & AF3 & DQ917616 \\
Perna perna & Cumaná, Venezuela & VZL1 & DQ917588 \\
& Cumaná, Venezuela & VZL2 & DQ917587 \\
& São Paulo, Brasil & SP1 & DQ917592 \\
& São Paulo, Brasil & SP2 & DQ917592 \\
& Santa Catarina, Brasil & SC1 & - \\
\multirow{4}{*}{ Mytilus edulis } & Santa Catarina, Brasil & SC2 & - \\
& Reino Unido & Myt1 & DQ917606 \\
Aulacomya atra maoriana & Reino Unido & Myt2 & DQ917605 \\
& Wellington, Nova Zelândia & Aul1 & DQ917614 \\
& Wellington, Nova Zelândia & Aul2 & DQ917615 \\
\hline
\end{tabular}

A inferência filogenética das sequências foi realizada por análises de neighbor-joining $(\mathrm{NJ})$ e maximum-likelihood (ML), utilizando-se o software MEGA v. 5.0 (Tamura et al., 2011). Na análise NJ foi usado o modelo Kimura 2parameter. O teste para a presença de relógio molecular foi executado (Ho: há presença de relógio molecular) mediante o método ML. Todas as posições que continham "gaps" ou dados faltantes foram excluídas. Valores de bootstrap foram calculados com 1000 replicações em todas as análises.

A divergência genética foi realizada empregando-se o pacote de softwares BEAST (Drummond et al., 2012). O estudo foi baseado em arquivo gerado utilizando a interface 'BEAUTI', e as configurações usadas foram as padrões, exceto para os valores dos seguintes parâmetros: menu Data - datas especificadas como anos antes do presente (BP); menu Modelo - frequência de bases estimada, local de heterogeneidade como modelo gama. Taxa média de substituição, modelo de relógio molecular estrito; menu de Priores - árvore antes: especiação Yule.

$\mathrm{Na}$ análise de Monte Carlo em cadeias de Markov após a geração de 1.000 .000 gerações, 10.000 amostras foram coletadas a cada 100 gerações. O ponto de calibração usado foi de 3.5 milhões de anos (MY) com base no ponto de divergência entre populações do Atlântico Norte de Mytilus trossulus e Mytilus edulis, de acordo com Wares e Cunningham (2001) e Riginos et al. (2004).
A convergência posterior foi avaliada mediante $o$ uso do software Tracer 1.4, concatenando-se as quatro corridas em uma árvore final com as idades dos nós estimadas como a média do valor de densidade mais elevada posterior a $95 \%$ (HPD).

\section{RESULTADOS}

O levantamento bibliográfico revelou a citação da espécie Perna perna e suas sinonímias em diversos sítios arqueológicos não datados (Tab. 2) e datados (Tab. 3) da costa brasileira.

As escavações do sítio arqueológico Rio do Meio, realizadas entre os anos de 1986 e 1989, revelaram que esse sítio apresentou duas unidades arqueológicas espacialmente isoladas por um intervalo de 58 metros, que foram

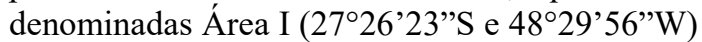
e Área II $\left(27^{\circ} 26^{\prime} 26^{\prime \prime} \mathrm{S}\right.$ e 48 $29^{\circ} 58^{\prime \prime}$ W). Morfologicamente, ambas as Áreas estavam estruturadas por sucessivas camadas de sedimentos arenosos, intercalados por estratos de conchas associadas a outros vestígios arqueológicos, como fragmentos de cerâmica, cinza e carvão. Em termos culturais, ambas as unidades preservaram vestígios cerâmicos produzidos por grupos vinculados a uma mesma tradição cultural, ou seja, a pré-colonial Jê. Os grupos pré-coloniais Jê, provavelmente, passaram a ocupar terras do litoral catarinense a partir de 1.000 anos BP. 
Tabela 2. Trabalhos que citam a presença de Perna perna em sítios arqueológicos não datados do litoral brasileiro

\begin{tabular}{llll}
\hline Referência & Espécie & Sítio & Região \\
\hline Leonardos (1938) & Mytilus perna & Cotia-Pará & Cubatão/SP \\
Leonardos (1938) & M. perna & Vila & Torres/RS \\
Leonardos (1938) & M. perna & Mampituba & Torres/RS \\
Rohr (1969) & Mytilus perna & Lagoa da Figueirinha & Jaguaruna/SC \\
$\operatorname{Rohr}(1969)$ & M. perna & Campo Bom & Jaguaruna/SC \\
$\operatorname{Rohr}(1969)$ & M. perna & Arroio da Cruz & Jaguaruna/SC \\
$\operatorname{Rohr}(1969)$ & M. perna & Morro Grande & Jaguaruna/SC \\
$\operatorname{Rohr}(1969)$ & M. perna & Olho d'Água & Jaguaruna/SC \\
$\operatorname{Rohr}(1969)$ & M. perna & Ponta do Morro & Jaguaruna/SC \\
$\operatorname{Rohr}(1969)$ & M. perna & Arrio da Cruz de Dentro & Jaguaruna/SC \\
$\operatorname{Rohr}(1969)$ & M. perna & Ilhota da Ponta do Morro & Jaguaruna/SC \\
Kneip (1977) & Perna perna & Forte & Cabo Frio/RJ \\
\hline
\end{tabular}

Tabela 3. Trabalhos que citam a presença de Perna perna em sítios arqueológicos datados do litoral brasileiro

\begin{tabular}{lllll}
\hline Referência & Espécie & Sítio & Região & Datação \\
\hline Piazza (1966) & M. perna & Espinheiros I & Joinville/SC & 970a.C. \\
Hurt (1974) & M. perna & Ponta das Almas & Florianópolis/SC & 1627a.C. \\
Rohr (1977) & M. perna & Pântano do Sul & Florianópolis/SC & 1722a.C. \\
Rohr (1977) & M.perna & Pântano do Sul & Florianópolis/SC & 1837a.C. \\
Rohr (1977) & M.perna & Pântano do Sul & Florianópolis/SC & 2447a.C. \\
Kneip (1994) & Perna perna & Moa & Saquarema/RJ & 1597a.C. \\
Kneip (1994) & M. perna & Moa & Saquarema/RJ & 1947a.C. \\
\hline
\end{tabular}

A datação das conchas do sítio arqueológico do norte da Ilha de Santa Catarina por $\mathrm{C}^{14}$ via AMS revelou idade dos fragmentos das conchas da Área I de $780 \pm 30$ BP e da Área II de $720 \pm 30$ BP, respectivamente (Tab. 4). Os resultados apontam a presença de Perna perna no litoral brasileiro antes mesmo do descobrimento do país no ano de 1500 , indicando que esses animais faziam parte da dieta das populações humanas nativas do Brasil.

Tabela 4. Resultados da datação por $\mathrm{C}^{14}$ das conchas coletadas das Áreas I e II do sítio arqueológico Rio do Meio (Florianópolis/SC, Brasil)

\begin{tabular}{clll}
\hline Amostra & Pré-tratamento & $\Delta \mathrm{R}$ & Datação \\
\hline I & Ácido & 117 & $780 \pm 30 \mathrm{BP}$ \\
II & Ácido & 117 & $720 \pm 30 \mathrm{BP}$ \\
\hline
\end{tabular}

Os resultados apontam uma clara distinção das populações estudadas, ficando evidente a diferenciação dos táxons africanos e sulamericanos nos cladogramas originados pelos dois métodos (Fig. 3). Os valores de bootstraps variaram bastante nos três modelos. Valores altos de boostraps (91-100) foram encontrados na árvore de ML, exceto pelo valor 68 encontrado no modelo. Já no modelo $\mathrm{NJ}$, os valores de bootstraps ficaram em uma faixa alta (98-100), exceto pelo ponto de divergência entre os ramos das populações venezuelanas e africanas, onde o valor foi 52. A hipótese de presença de relógio molecular foi comprovada $(\mathrm{P}>0,05)$. Isso significa que a metodologia prevista pode ser aplicada.

O tempo de divergência encontrado entre as populações africanas e sul-americanas foi de aproximadamente 200 mil anos (Fig. 4). 

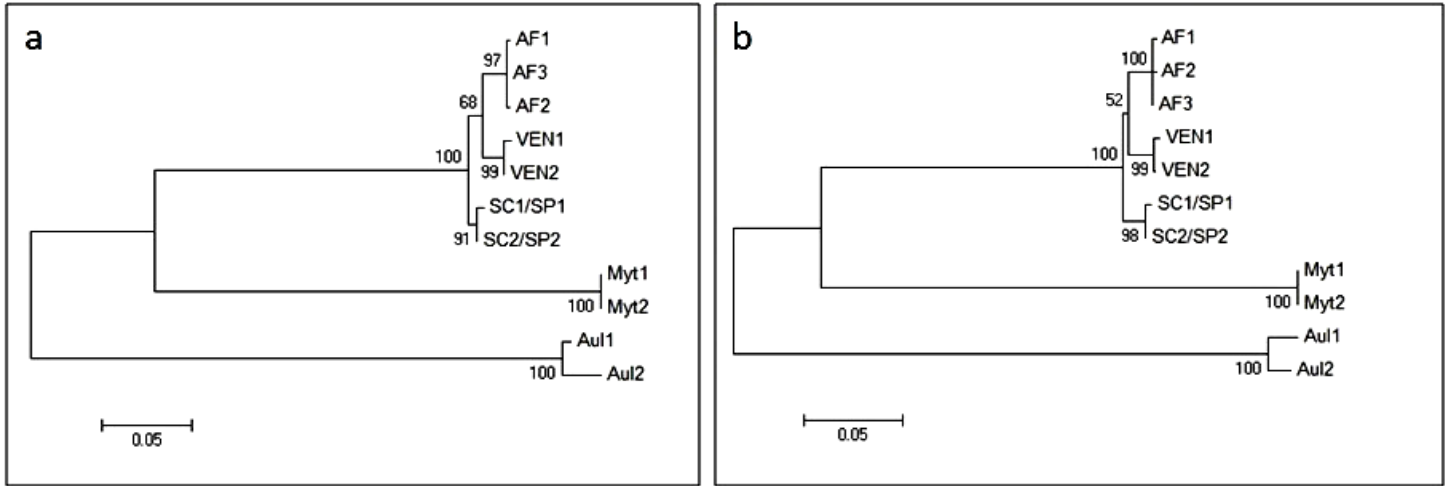

Figura 3. Árvores filogenéticas geradas: a - Maximum Likelihood, b - Neighbor Joing. Legenda: AF1, AF2 e AF3 - sequências africanas, VEN1 E VEN2 - sequências venezuelanas, SC1/SP1, SC2/SP2 sequências brasileiras, Myt1 e Myt2 - sequências do gênero Mytilus, Aul1 e Aul2 - sequências de Aulocomya atra amoriana. Valores de bootstrap foram calculados com 1000 repetições.

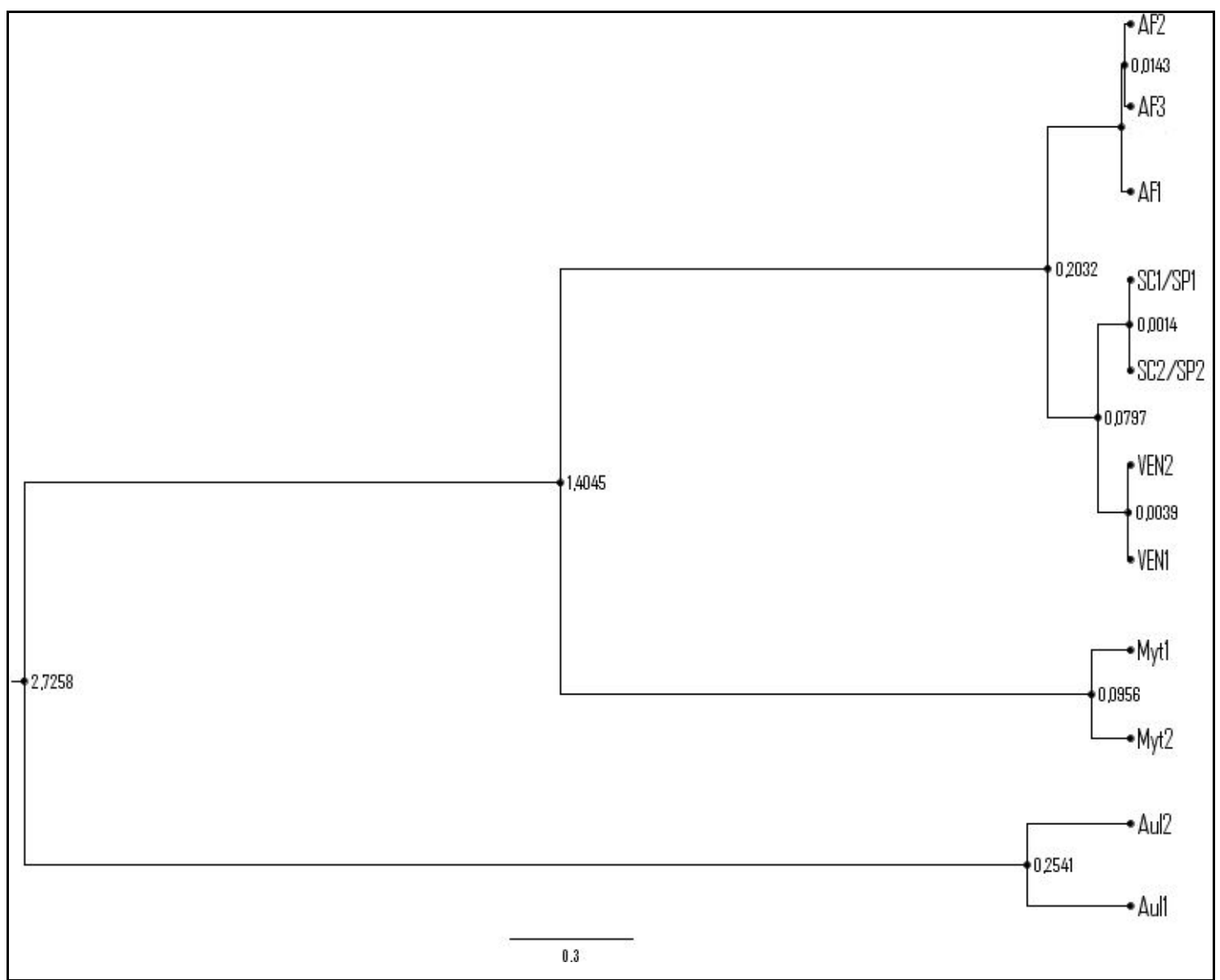

Figura 4. Cladograma do cálculo do tempo de divergência entre as populações. Legenda: AF1, AF2 e AF3 - sequências africanas, VEN1 E VEN2 - sequências venezuelanas, SC1/SP1, SC2/SP2 - sequências brasileiras, Myt1 e Myt2 - sequências do gênero Mytilus, Aul1 e Aul2 - sequências de Aulocomya atra maoriana. Valores dados em milhões de anos. 


\section{DISCUSSÃO}

Entre os diversos trabalhos encontrados que comprovam a presença da espécie Perna perna em sítios arqueológicos brasileiros, Kneip (1977) cita que o Sambaqui do Forte, município de Cabo Frio/RJ, apresentava grande quantidade da espécie em sua composição. A autora ainda relata que a presença das conchas da espécie, apesar de estas estarem muito fragmentadas, prova a grande importância desse mexilhão na alimentação das populações humanas nativas daquele sambaqui.

Mytilus perna, hoje $P$. perna (Siddall, 1980) foi encontrado nos sambaquis de Cotia-Pará (Cubatão/SP) e da Vila, na cidade de Torres/RS (Leonardos, 1938). Na região de Santa Catarina, são vários os sambaquis em que Mytilus foram encontrados, entre eles, podem-se citar os sambaquis nas localidades de Lagoa da Figueirinha, Campo Bom, Arroio da Cruz, Morro Grande, Arroio da Cruz de Dentro, Olho d'Água e Ponta do Morro (Rohr, 1969).

Os resultados encontrados na datação realizada nas conchas apontam a presença da espécie antes mesmo da chegada dos descobridores do país. Estudos realizados por renomados arqueólogos brasileiros suportam os resultados encontrados. Estes trabalhos (Piazza, 1966; Hurt, 1974; Rohr, 1977; Kneip, 1994) citam que o marisco estava presente em sambaquis do sul e sudeste do Brasil no período pré-descobrimento.

Os sítios, alguns inclusive sem interferência antrópica recente, apontaram representativa presença de conchas de mariscos. Nessa linha, é possível relacionar o sambaqui de Ponta das Almas (leste da Ilha de Santa Catarina/Santa Catarina - Brasil), estudado em 1966 por Hurt (1974), em que conchas de Mytilus perna, hoje Perna perna (Siddall, 1980), foram encontradas em um estrato de $0,60 \mathrm{~m}$ datado por radiocarbono em 3620 +/- 100 BP ou seja, 1627 a.C. Piazza (1966) encontrou quantidades relevantes de Mytilus, hoje Perna (Siddall, 1980), no sambaqui de Espinheiros I (Joinvile/Santa Catarina Brasil), que foi datado em 970 a.C.

No sambaqui do Moa (Saquarema/RJ - Brasil), foram encontradas conchas de Perna perna nas duas camadas estudadas, datadas por radiocarbono: camada I, 1597 a.C., camada II,
1947 a.C. (Kneip, 1994). A autora ainda completa que evidências demonstram que os habitantes do sambaqui de Moa coletavam $P$. perna de maior porte em pequenas quantidades e também explica que, devido à fragilidade da concha de $P$. perna, esta normalmente se encontra fragmentada, fato que dificulta sua identificação e que talvez explique a ausência de mais citações da espécie em outros trabalhos. A concha de Perna perna é muito menos resistente à compactação do que conchas de ostras e berbigões. Considerado como "maior escavador brasileiro", o padre João Alfredo Rohr cita, em 1977, a presença de Mytilus perna (hoje $P$. perna) no sítio Pântano do Sul (Florianópolis), que teve algumas faixas datadas naquela época em $3.735,3.850$ e 4.460 anos.

O resultado da inferência filogenética está de acordo com os encontrados por Wood et al. (2007), em que o tempo de divergência entre populações brasileiras e africanas do mexilhão Perna perna estaria entre 0,17 e 0,57 milhões de anos. Holland (2001), ao avaliar populações de $P$. perna no Golfo do México, utilizando microssatélites, verificou que a população de mexilhões brasileira é geneticamente diferente das populações africanas analisadas, sendo colocada filogeneticamente próxima de populações americanas, como a mexicana e a venezuelana, e distante das populações africanas.

Estudo realizado por Rius e McQuaid (2009) indica que a sobrevivência da espécie $P$. perna em zonas médias está fortemente relacionada com a densidade dos animais. O estudo aponta que, em densidades abaixo de 25 animais por metro quadrado, a sobrevivência de mexilhões adultos cai se comparada com áreas com o dobro da densidade. Esses resultados fragilizam a hipótese de que a colonização da espécie no Brasil tenha se dado a partir de poucos animais incrustados em cascos de navios negreiros durante o século XVI, uma vez que a densidade seria baixa.

Fator também relevante é a baixa presença de outros mitilídeos exclusivamente marinhos na costa brasileira. Os mitilídeos são importantes componentes na estrutura do litoral rochoso em todos os continentes. Mesmo que tivesse ocorrido uma colonização tardia de Perna perna no litoral brasileiro, seria comum encontrar outros mitilídeos marinhos ao longo da costa, 
uma vez que $P$. perna apresenta dificuldades de habitar zonas rochosas mais profundas (Bownes e McQuaid, 2006; Rius e McQuaid, 2009), o que diminuiria a pressão competitiva sobre outras possíveis espécies nativa.

Além dos argumentos supracitados, outros pontos ainda podem ser abordados na discussão para se compreender a origem do mexilhão no Brasil. Entre esses pontos, as relações da fauna nativa associada e dependente do microambiente fornecido pelas populações naturais de mexilhão, reconhecido bioatrator de diversidade, devem ser citadas. Outro ponto importante é a relação hospedeiro-parasita que ocorre entre o Perna perna e seus patógenos nativos. Essas relações não se estabelecem em períodos de tempo curto como o sugerido, e sim ao longo de milhares de anos de coexistência.

\section{CONCLUSÃo}

Com base nos resultados arqueológicos encontrados, datação de $\mathrm{C}^{14}$ e biologia molecular, suportados pela literatura científica clássica e recente, fica clara a condição de nativa da espécie Perna perna no litoral brasileiro, estando presente antes do descobrimento do país pelos europeus.

\section{REFERÊNCIAS}

BENNETT, C.L.; BEUKENS, R.P.; CLOVER, M.R. et al. Radiocarbon dating using electrostatic accelerators: negative ions provide the key. Science, v.198, p.508-510, 1977.

BIRKY, C.W.; FUERST, P.; MARUYAMA, T. Organelle gene diversity under migration, mutation, and drift: equilibrium expectations, approach to equilibrium, effect of heteroplasmic cells, and comparison to nuclear genes. Genetics, v.121, p.613-627, 1989.

BOWNES, S.J.; McQUAID, C.D. Will the invasive mussel Mytilus galloprovincialis Lamarck replace the indigenous Perna perna L. on the south coast of South Africa? J. Exp. Mar. Biol. Ecol., v.338, p.140-151, 2006.

COOPER, J.; THOMAS, K.D. Constructing caribbean chronologies: comparative radiocarbon dating of shell and wood artefacts from precolumbian sites in Cuba. Archaeometry, v.54, p.401-425, 2012.
DRUMMOND, A.J.; SUCHARD, M.A.; XIE, D.; RAMBAUT, A. Bayesian phylogenetics with BEAUti and the BEAST 1.7. Mol. Biol. Evol., v.29, p.1969-1973, 2012.

FERNANDES, F.C. Distribuição mundial e o impacto de sua introdução no Brasil. In: RESGALLA-JUNIOR, C.; WEBER, L.I.; CONCEIÇÃO, M.B. (Eds.). O mexilhão Perna perna (L.). Rio de Janeiro: Interciência, 2008. p.27-30.

FERREIRA, J.F.; MAGALHÃES, A.R.M. Cultivo de mexilhões. In: POLI, A.T.B.; ANDREATTA, E.R.; BELTRAME, E. (Eds.). Aquicultura: experiências brasileiras. Florianópolis: Multitarefa, 2004. p.221-250.

FOLMER, O.; BLACK, M.; HOEH, W. et al. DNA primers for amplification of mitochondrial cytochrome c oxidase subunit I from diverse metazoan invertebrates. Mol. Mar. Biol. Biotechnol., v.3, p.294-299, 1994.

FREITAS, M.O.; VELASTIN, R. Ictiofauna associada a um cultivo de mexilhão Perna perna (Linnaeus, 1758) norte Catarinense, sul do Brasil. Acta Sci. Biol. Sci., v.32, p.31-37, 2010.

HICKS, D.W.; McMAHON, R.F. Respiratory responses to temperature and hypoxia in the nonindigenous Brown Mussel, Perna perna (Bivalvia: Mytilidae), from the Gulf of Mexico. J. Exp. Mar. Biol. Ecol., v.277, p.61-78, 2002.

HOLLAND, B. Invasion without a bottleneck: microsatellite variation in natural and invasive populations of the brown mussel Perna perna (L). Mar. Biotechnol., v.3, p.407-415, 2001.

HULME, P.E. Trade, transport and trouble: managing invasive species pathways in an era of globalization. J. Appl.Ecol., v.46, p.10-18, 2009.

HURT, W.R. The Interrelationships between the natural environment and four sambaquís, coast of Santa Catarina, Brazil. Occas. Pap. Monog. Indiana Univ. Mus., v.1, p.1-23, 1974.

KILADA, R.; CAMPANA, S.; RODDICK, D. Growth and sexual maturity of the northern propellerclam ( Cyrtodaria siliqua ) in eastern Canada, with bomb radiocarbon age validation. Mar. Biol., v.156, p.1029-1037, 2009.

KNEIP, L.M. Pescadores e coletores préhistóricos do litoral de Cabo Frio, RJ. São Paulo: Coleção Museu Paulista, 1977. 169p. 
KNEIP, L.M. Cultura material e subsistência das populações pré históricas de Saquarema, RJ. Rio de Janeiro: Museu Nacional/UFRJ, 1994. 119 p.

LEONARDOS, O.H.. Concheiros naturais $e$ sambaquís. Rio de Janeiro: Ministério da Agricultura, 1939. 109p.

LIU, Z.J.; CORDES, J.F. DNA marker technologies and their applications in aquaculture genetics. Aquaculture, v.238, p.1-37, 2004.

MACK, R.; SIMBERLOFF, D.; LONSDALE, W. et al. Biotic invasions: causes, epidemiology, global consequences, and control. Ecol. Appl., v.10, p.689-710, 2000.

MARENZI, A.W.C.; BRANCO, J.O. O cultivo do mexilhão Perna perna no município de Penha, SC. In: BRANCO, J.O.; MARENZI, A.W.C. (Eds.). Bases ecológicas para um desenvolvimento sustentável: estudos de caso em Penha, SC. Itajaí: UNIVALI, 2006. p.227-244.

McGEOCH, M. A.; BUTCHART, S.H.M.; SPEAR, D. et al. Global indicators of biological invasion: species numbers, biodiversity impact and policy responses. Div. Dist., v.16, p.95-108, 2010 .

PIAZZA, W. F. Estudos de sambaquís: nota prévia. Florianópolis: Imprensa Universitária UFSC, 1966. 72p. (Série arqueologia, 2)

RICK, T.C.; VELLANOWETH, R.L.; ERLANDSON, J.M. Radiocarbon dating and the "old shell" problem: direct dating of artifacts and cultural chronologies in coastal and other aquatic regions. J. Arch. Sci., v.32, p.1641-1648, 2005.

RIGINOS, C.; HICKERSON, M.J.; HENZLER, C.M.; CUNNINGHAM, C.W. Differential patterns of male and female mtDNA exchange across the atlantic ocean in the blue mussel, Mytilus edulis. Evolution, v.58, p.2438-2451, 2004.

RIOS, E.C. (Ed.). Compendium of brazilian sea shells. Rio Grande: UFRG, 2009. 668p.

RIUS, M.; McQUAID, C.D. Facilitation and competition between invasive and indigenous mussels over a gradient of physical stress. Bas. Appl. Ecol., v.10, p.607-613, 2009.
ROHR, Pe. J. A. O sítio arqueológico do Pântano do Sul. Florianópolis: IOESC, 1977. $114 \mathrm{p}$.

ROHR, Pe. J. A. Os sítios arqueológicos do município sul-catarinense de Jaguaruna. São Leopoldo: Instituto Anchietano de Pesquisas, 1969. 37p. (Série antropologia, 22)

RUIZ, G.; CARLTON, J.; GROSHOLZ, E.; HINES, A. Global invasions of marine and estuarine habitats by non-indigenous species: mechanisms, extent, and consequences. Am. Zool., v.37, p.621-632, 1997.

SALOMÃO, L.C.; MAGALHÃES, A.R.M.; LUNETA, J.E. Influência da salinidade na sobrevivência de Perna perna (Mollusca: Bivalvia). Bol. Fisiol. Anim., v.4, p.143-152, 1980.

SIDDALL, S.E. A clarification of the genus Perna (mytilidae). Bull. Mar. Sci., v.30, p.858$870,1980$.

SOUZA, R.C.C.L. de.; FERNANDES, F.C.; SILVA, E.P. A study on the occurrence of the brown mussel Perna perna on the sambaquis of the brazilian coast. Rev. Mus. Arqueol. Etnol., v.13, p.3-24, 2003.

SOUZA, R.C.C.L.; TRINDADE, D.C.; DECCO, $\mathrm{J}$. et al. Archaeozoology of marine mollusks from sambaqui da Tarioba, Rio das Ostras, Rio de Janeiro, Brazil. Zool., v.27, p.363-371, 2010.

TAKADA, M.; TANI, A.; MIURA, H. et al. ESR dating of fossil shells in the Lützow-Holm Bay region, east Antarctica. Quat. Sci. Rev., v.22, p.1323-1328, 2003.

TAMURA, K.; PETERSON, D.; PETERSON, $\mathrm{N}$. et al. MEGA5: molecular evolutionary genetics analysis using maximum likelihood, evolutionary distance, and maximum parsimony methods. Mol. Biol. Evol., v.28, p.2731-2739, 2011.

VÉLEZ, R.A.; EPIFANIO, C.E. Effects of temperature and ration on gametogenesis and growth in the tropical mussel Perna perna (L.). Aquaculture, v.22, p.21-26, 1981.

VELLANOWETH, R.L. AMS radiocarbon dating and shell bead chronologies: middle holocene trade and interaction in western North America. J. Archael. Sci., v.28, p.941-950, 2001. 
WANAMAKER JR, A.D.; HEINEMEIER, J.; SCOURSE, J.D. et al. Very long-lived mollusks confirm 17th century ad tephra-based radiocarbon reservoir ages for north icelandic shelf waters. Radiocarbon, v.50, p.399-412, 2008.

WARES, J.P.; CUNNINGHAM, C.W. Phylogeography and historical ecology of the north atlantic intertida. Evolution, v.55, p.24552469, 2001.
WOOD, A.R.; APTE, S.; MacAVOY, E.S.; GARDNER, J.P.A. A molecular phylogeny of the marine mussel genus Perna (Bivalvia: Mytilidae) based on nuclear (ITS1\&2) and mitochondrial (COI) DNA sequences. Mol. Phylogenet. Evol., v.44, p.685-698, 2007. 